\title{
Avaliação das propriedades físico-mecânicas de uma massa cerâmica para revestimento poroso (BIII)
}

\section{(Evaluation of physical-mechanical properties of a ceramic paste for porous wall tile (BIII))}

\author{
S. J. G. Sousa, J. N. F. Holanda \\ CCT-LAMAV, Universidade Estadual do Norte Fluminense \\ Av. Alberto Lamego 2000, Campos dos Goytacazes, RJ 28013-602 \\ holanda@uenf.br
}

\begin{abstract}
Resumo
O presente trabalho teve por objetivo estudar as propriedades físico-mecânicas de uma massa para revestimento cerâmico poroso base vermelha a partir de matérias-primas da região Norte Fluminense. A massa cerâmica preparada pelo processo via seca foi caracterizada quanto a composição química, análise de tamanho de partícula, difração de raios $\mathrm{X}$ e comportamento térmico. Os corpos cerâmicos foram prensados sob $35 \mathrm{MPa}$ e sinterizados entre 1080 e $1200{ }^{\circ} \mathrm{C}$ usando um ciclo de queima rápido. A microestrutura sinterizada foi avaliada por microscopia eletrônica de varredura. Os corpos cerâmicos sinterizados exibiram baixos valores de retração linear, resultando em boa estabilidade dimensional. A microestrutura é caracterizada por alta porosidade. Além disso, foram atingidas as especificações para revestimento poroso (NBR 13818) em termos da tensão de ruptura à flexão e da absorção de água dos corpos cerâmicos sinterizados, indicando o potencial das matérias-primas cerâmicas do Norte Fluminense para este tipo de aplicação.

Palavras-chave: revestimento poroso, sinterização, microestrutura.
\end{abstract}

Abstract

The present work aimed at studying the physical-mechanical properties of a ceramic paste for red porous wall tile using raw materials from the Northern Fluminense region. The ceramic paste was prepared by dry process and characterized regarding chemical composition, particle size analysis, X-ray diffraction and thermal behavior. The ceramic bodies were pressed under 35 $\mathrm{MPa}$ and sintered from 1080 to $1200{ }^{\circ} \mathrm{C}$ in a fast-firing cycle. The sintered microstructure was evaluated by scanning electron microscopy. The results showed that the sintered ceramic bodies exhibited low values of linear shrinkage, resulting in good dimensional stability. The microstructure was characterized by high porosity. In addition, the specifications for porous wall tiles (NBR 13818) were achieved in terms of the flexural strength and water absorption of the sintered ceramic bodies, indicating the potential of the ceramic raw materials of the region for this application.

Keywords: porous wall tile, sintering, microstructure.

\section{INTRODUÇÃO}

Nos últimos anos, devido ao amplo interesse demonstrado pelo mercado e fabricantes [1], os produtos de revestimento poroso (azulejos) assumiram grande importância. Este tipo de produto cerâmico pertence especificamente ao grupo BIII de acordo com a classificação da norma Brasileira NBR 13818 [2]. Em geral, aos materiais de revestimento poroso são atribuídas algumas características como: máxima estabilidade dimensional durante a queima [3], porosidade aberta entre 10 e $20 \%$ (expressa como a capacidade de absorção de água) e valores de tensão de ruptura à flexão do produto sinterizado iguais ou superiores a $12 \mathrm{MPa}$, para placas cerâmicas com espessura superior ou igual a 7,5 mm e superiores ou iguais a $15 \mathrm{MPa}$, para placas com espessura inferiores a 7,5 $\mathrm{mm}[2]$.

As massas cerâmicas nacionais possuem em sua formulação principalmente argilas, calcita, dolomita, feldspato, quartzo e talco [4]. A proporção entre os minerais presentes nas massas cerâmicas, junto às condições de processamento influenciam diretamente as propriedades do produto acabado. As misturas, porém, mantêm a necessidade de permitir a formação de fases cristalinas compostas de silicatos e aluminossilicatos de cálcio e/ou magnésio durante a sinterização [5]. A formação destas fases, precedida de intensa desgaseificação, caracteriza a produção de azulejo sinterizado em uma única queima.

A região Norte Fluminense dispõe de grandes reservas de matérias-primas cerâmicas. O Pólo Cerâmico instalado no município de Campos dos Goytacazes, apesar de ser 
um dos mais importantes do estado do Rio de Janeiro, com cerca de $35 \%$ das empresas e $35 \%$ da produção, fabrica somente produtos de cerâmica vermelha, principalmente blocos cerâmicos de vedação, tijolos e telhas [6]. Por isso, o desenvolvimento de novos produtos de maior valor agregado, tais como os revestimentos cerâmicos (piso e parede), é de fundamental importância para o crescimento da indústria cerâmica local, além do desenvolvimento econômico da região.

O principal objetivo deste trabalho é o estudo das propriedades físico- mecânicas de uma massa cerâmica para revestimento poroso (BIII), base vermelha, preparada com matérias-primas da região Norte Fluminense. Destaque foi dado às características químicas, mineralógicas e físicas da massa cerâmica. É feita uma correlação entre estas características e as propriedades do produto sinterizado, bem como a microestrutura final das peças obtidas.

\section{MATERIAIS E MÉTODOS}

\section{Materiais}

Para a formulação da massa cerâmica foram utilizadas as seguintes matérias-primas: uma massa argilosa fornecida por uma indústria cerâmica, localizada no município de Campos dos Goytacazes-RJ, um calcário proveniente do município de Italva-RJ, quartzo e talco comercial. As composições químicas das matérias-primas determinadas por fluorescência de raios X são dadas na Tabela I. A composição da massa cerâmica estudada é dada na Tabela II. A descrição detalhada da formulação da massa é dada na referência [7].

A massa argilosa foi recebida na forma de torrões. Inicialmente, foi deixada ao ar livre para retirada do excesso de umidade e posteriormente seca em estufa a $110{ }^{\circ} \mathrm{C}$, por $24 \mathrm{~h}$. Os torrões foram desagregados em pilão manual. Em seguida, a massa argilosa foi moída a seco em moinho de bolas (Gardelin, modelo 1A MB5) até a não retenção do pó em peneira de 200 mesh (75 $\mu \mathrm{m}$ ABNT). O calcário, recebido na forma de pó, foi seco em estufa a $110{ }^{\circ} \mathrm{C}$ por
Tabela II - Composição da massa cerâmica estudada. [Table II - Composition of the studied ceramic paste.].

\begin{tabular}{cccc}
\hline \multicolumn{4}{c}{ Matérias-primas (\% em peso) } \\
\hline Argila & Calcário & Quartzo & Talco \\
\hline 70 & 15 & 10 & 5 \\
\hline
\end{tabular}

$24 \mathrm{~h}$ e passado em peneira de 200 mesh. O quartzo e o talco, também recebido na forma de pó, foram fornecidos numa granulometria inferior a 200 mesh e, portanto, foram utilizados conforme recebidos.

\section{Metodologia}

A dosagem da massa cerâmica foi feita por pesagem. A massa foi então submetida a um processo de microgranulação. O processo consistiu na mistura, homogeneização e microgranulação da massa cerâmica, realizada num microgranulador intensivo (EIRICH, modelo R02). Em seguida, foi feito o controle da umidade da massa cerâmica para cerca de 7\% (base seca). Os aglomerados grossos, maiores que $2 \mathrm{~mm}$, foram eliminados do processo.

Análises de difração de raios $\mathrm{X}$ foram realizadas em difratômetro Seifert, modelo URD 65, com radiação $\mathrm{Cu}-\mathrm{K} \alpha$ na faixa angular $5^{\circ} \leq 2 \theta \leq 60^{\circ}$. Análises térmicas ATD/ATG/ DTG foram realizadas em analisador térmico simultâneo, TA Instruments, modelo SDT-2960, ao ar entre a temperatura ambiente $\left(\sim 25{ }^{\circ} \mathrm{C}\right)$ e $1150{ }^{\circ} \mathrm{C}$, com taxa de aquecimento de $10{ }^{\circ} \mathrm{C} \cdot \mathrm{min}^{-1}$.

A distribuição de tamanho das partículas primárias que compõem a massa cerâmica foi obtida de acordo com a norma NBR 7181-84 [8], combinando técnicas de peneiramento e sedimentação. A distribuição de tamanho de partículas da massa granulada foi feita por peneiramento.

Corpos cerâmicos retangulares $\left(115,0\right.$ x 25,4 x 7,5 mm $\left.\mathrm{mm}^{3}\right)$ foram prensados uniaxialmente sob $35 \mathrm{MPa}$. Após a compactação, os corpos verdes foram secos em estufa a $110{ }^{\circ} \mathrm{C}$ por $24 \mathrm{~h}$ e

Tabela I - Composições químicas das matérias-primas (\% em peso).

[Table I - Chemical compositions (wt.\%) of the raw materials.]

\begin{tabular}{lcccccccccccccc}
\hline Material & $\mathrm{SiO}_{2}$ & $\mathrm{Al}_{2} \mathrm{O}_{3}$ & $\mathrm{Fe}_{2} \mathrm{O}_{3}$ & $\mathrm{CaO}$ & $\mathrm{Na}_{2} \mathrm{O}$ & $\mathrm{K}_{2} \mathrm{O}$ & $\mathrm{MnO}$ & $\mathrm{TiO}_{2}$ & $\mathrm{MgO}$ & $\mathrm{P}_{2} \mathrm{O}_{5}$ & $\mathrm{P.F}$. \\
\hline Argila & 46,42 & 27,90 & 9,10 & 0,22 & 0,36 & 1,67 & 0,11 & 1,32 & 0,71 & 0,21 & 11,96 \\
\hline Calcário & 6,01 & 0,81 & 0,55 & 47,26 & 0,15 & 0,23 & 0,01 & 0,06 & 4,91 & 0,07 & 39,94 \\
\hline Quartzo & 99,66 & 0,15 & 0,04 & - & - & - & - & 0,01 & - & - & 0,25 \\
\hline Talco & 59,53 & 1,59 & 3,94 & 0,07 & 0,01 & 0,01 & 0,02 & 0,04 & 29,26 & 0,02 & 5,53 \\
\hline
\end{tabular}

P.F. = Perda ao fogo 
sinterizados em forno de queima rápida MAITEC, modelo FSQC1300/3, com máximas temperaturas de sinterização variando de 1080 até $1200{ }^{\circ} \mathrm{C}$, e ciclo de queima de aproximadamente $1 \mathrm{~h}$. Os corpos cerâmicos sinterizados foram avaliados por meio das seguintes propriedades: retração linear, absorção de água, massa específica aparente e tensão de ruptura à flexão (ensaio de carregamento em três pontos). Além disso, a morfologia da superfície de fratura dos corpos cerâmicos sinterizados, foi analisada em microscópio eletrônico de varredura Zeiss modelo DSM 962, com voltagem de aceleração de $10 \mathrm{kV}$. O carregamento elétrico foi evitado recobrindo-se as amostras com uma fina camada condutora de ouro.

\section{RESULTADOS E DISCUSSÃO}

A Fig. 1 mostra o difratograma de raios $\mathrm{X}$ da massa cerâmica estudada. Verifica-se que a amostra é constituída das seguintes fases cristalinas: caulinita, ilita/mica, quartzo, gibsita, goetita, calcita, dolomita e talco. $\mathrm{O}$ argilomineral predominante é a caulinita, evidenciado pelos seus picos característicos bastante intensos e de forma bem definida. A ilita/mica foi detectada por linhas de difração menos intensas. A presença de gibsita é um indicativo de que parte do $\mathrm{Al}_{2} \mathrm{O}_{3}$ (Tabela $\mathrm{I}$ ) não está ligada à estrutura cristalina dos

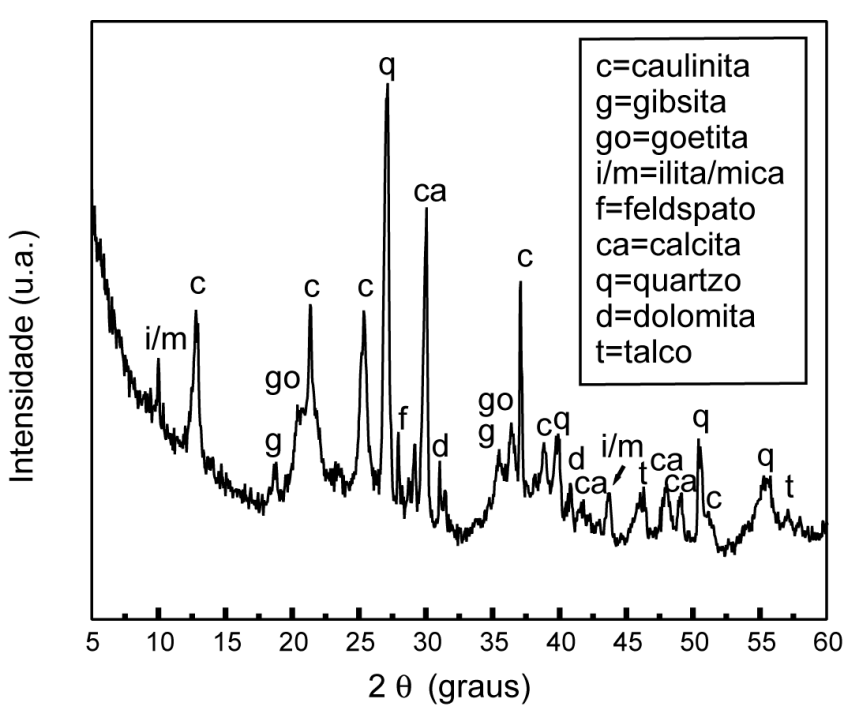

Figura 1: Difratograma de raios $X$ da massa cerâmica estudada. [Figure 1: X-ray diffraction pattern of the studied ceramic paste.]. argilominerais. A presença de goetita evidencia que parte do ferro presente está na forma de hidróxido. Os picos característicos de calcita se apresentaram de forma intensa e bem definida. A identificação de picos característicos de dolomita justifica a presença de $\mathrm{MgO}$. Além disso, é um indicativo de que nem todo $\mathrm{MgO}$ está associado à estrutura cristalina do mineral talco. Foram detectados ainda picos característicos de pouca intensidade de feldspato potássico.

A partir das composições químicas individuais das matériasprimas (Tabela I), calculou-se a composição química da massa cerâmica formulada [7], dada na Tabela III.

Verifica-se que a massa cerâmica é essencialmente constituída por $\mathrm{SiO}_{2}, \mathrm{Al}_{2} \mathrm{O}_{3}, \mathrm{CaO}$ e $\mathrm{Fe}_{2} \mathrm{O}_{3}$. O teor de $\mathrm{SiO}_{2}$ está associado à estrutura cristalina dos argilominerais, ao mineral talco e à introdução de quartzo na composição da massa cerâmica. Isto é consistente com os resultados de difração de raios $X$ (Fig. 1). Os revestimentos porosos devem apresentar boa estabilidade dimensional durante a sinterização, apresentando baixos valores de retração linear. O quartzo, devido a seu elevado ponto de fusão, garante a integridade estrutural das peças durante a sinterização [9]. O teor de $\mathrm{Al}_{2} \mathrm{O}_{3}$ obtido está associado à estrutura cristalina dos argilominerais e à presença de gibsita, e está de acordo com os resultados de difração de raios $\mathrm{X}$. O elevado teor de $\mathrm{CaO}$ está relacionado à presença de carbonato de cálcio $\left(\mathrm{CaCO}_{3}\right)$, presente no calcário adicionado à composição da massa cerâmica. A presença de carbonatos na massa cerâmica é de fundamental importância, pois garante a porosidade necessária a este tipo de revestimento [10]. O elevado teor de $\mathrm{Fe}_{2} \mathrm{O}_{3}$ está associado à argila utilizada (Tabela I), bem como caracteriza a massa cerâmica como uma massa de queima vermelha. $\mathrm{O}$ ferro está presente na forma de goetita e com $\mathrm{Fe}^{3+}$ em substituição parcial ao alumínio na rede cristalina da caulinita [11]. Com relação aos componentes menos frequientes, suas quantidades são pequenas: $\mathrm{Na}_{2} \mathrm{O}(0,27 \%)$, $\mathrm{K}_{2} \mathrm{O}(1,20 \%), \mathrm{MgO}(1,97 \%)$ e $\mathrm{TiO}_{2}(0,92 \%)$. Os teores de óxidos alcalinos $\left(\mathrm{K}_{2} \mathrm{O}\right.$ e $\left.\mathrm{Na}_{2} \mathrm{O}\right)$ são baixos e estão associados à presença de feldspatos na massa cerâmica e à estrutura cristalina de argilominerais como a ilita. O teor de $\mathrm{MgO}$ está associado à presença de dolomita presente no calcário e à estrutura cristalina do mineral talco. O elevado teor de perda ao fogo está relacionado à perda de água na forma de vapor e $\mathrm{CO}_{2}$, típico de massas para revestimento poroso.

$\mathrm{O}$ comportamento térmico da massa cerâmica foi avaliado por meio de curvas de análise térmica simultânea ATD/ATG/DTG, apresentadas na Fig. 2. Como pode ser

Tabela III - Composição química da massa cerâmica estudada.

[Table III - Chemical composition of the studied ceramic paste.].

\begin{tabular}{rcccccccccc}
\hline $\mathrm{SiO}_{2}$ & $\mathrm{Al}_{2} \mathrm{O}_{3}$ & $\mathrm{Fe}_{2} \mathrm{O}_{3}$ & $\mathrm{CaO}$ & $\mathrm{Na}_{2} \mathrm{O}$ & $\mathrm{K}_{2} \mathrm{O}$ & $\mathrm{MnO}$ & $\mathrm{TiO}_{2}$ & $\mathrm{MgO}$ & $\mathrm{P}_{2} \mathrm{O}_{5}$ & P.F. \\
\hline 46,37 & 19,73 & 6,65 & 7,25 & 0,27 & 1,20 & 0,08 & 1,12 & 1,97 & 0,16 & 14,64 \\
\hline
\end{tabular}

P.F. $=$ Perda ao fogo 
observada na curva de ATD, a massa cerâmica exibe quatro vales endotérmicos nas temperaturas de 27, 258, 490 e 714 ${ }^{\circ} \mathrm{C}$, respectivamente. Estes eventos, envolvendo perdas de massa de $1,28,2,12,5,85$ e 5,84\%, respectivamente, estão associados à remoção de água fisicamente adsorvida na superfície dos argilominerais, remoção de água de cristalização de hidróxidos (gibsita e goetita), desidroxilação da caulinita para formação de metacaulinita [12], e decomposição do carbonato de cálcio (calcita) para formar $\mathrm{CaO}$ e $\mathrm{CO}_{2}$ [13]. A massa cerâmica exibiu ainda um pico exotérmico na temperatura de $975{ }^{\circ} \mathrm{C}$, relacionado à destruição da rede cristalina do silicato para formar novas fases cristalinas à base de cálcio e/ou magnésio, silicatos e aluminossilicatos de cálcio e magnésio [13, 14]. Os eventos endotérmicos foram acompanhados por intensa transferência de massa, como mostra as curvas de ATG/DTG. A massa cerâmica apresentou, de acordo com a curva TG, uma perda de massa total de $14,77 \%$, aproximando-se do valor de perda ao fogo mostrado na composição química da massa cerâmica (Tabela III).

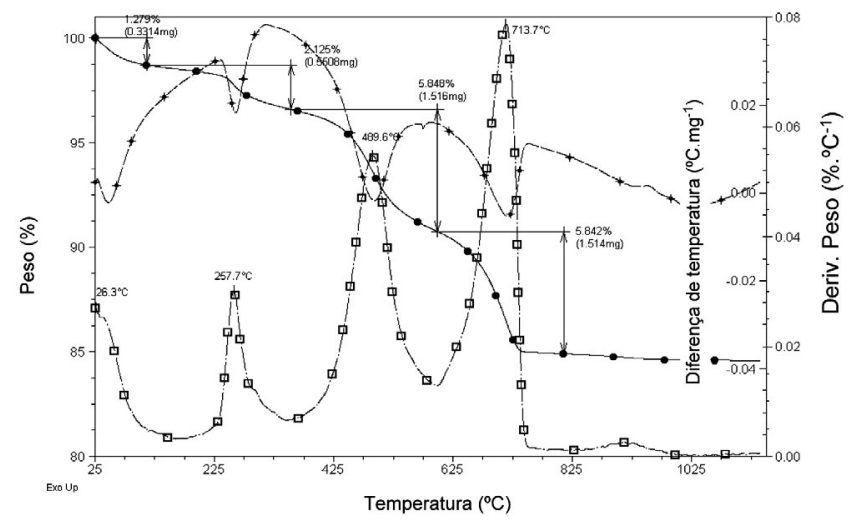

Figura 2: Curvas ATD/TG/DTG da massa cerâmica estudada. [Figure 2: DTA-TGA-DTG curves of the studied ceramic paste.]

A curva de distribuição de tamanhos das partículas primárias que compõem a massa cerâmica é mostrada na Fig. 3. Nota-se que, a massa cerâmica apresentou $93 \%$ de partículas com diâmetro esférico equivalente inferior a $60 \mu \mathrm{m}$. Isto significa que, a massa cerâmica possui um bom nível de cominuição, compatível com as massas convencionais para revestimento poroso base vermelha. Neste caso, os valores recomendados pela literatura [14], para percentuais de partículas superiores a $60 \mu \mathrm{m}$, estão centrados no intervalo compreendido entre 3-8\% do total da massa cerâmica. Quanto mais fina for a granulometria da massa cerâmica, maior será a reatividade entre as partículas durante a sinterização. Uma boa reatividade entre as partículas irá favorecer as reações de formação de novas fases cristalinas à base de cálcio e/ou magnésio, cuja proporção afeta significativamente as propriedades físico-mecânicas das peças sinterizadas. Se por um lado a reatividade aumenta com a diminuição do tamanho médio das partículas, por outro pode ocorrer a diminuição da compacidade da massa cerâmica para determinada pressão de compactação e umidade. Partículas excessivamente finas dificilmente sofrem redução significativa do seu volume durante a compactação. Estas partículas contribuem muito pouco para o aumento da massa específica dos compactos verdes. Por isso, a massa cerâmica foi submetida a um processo de microgranulação.

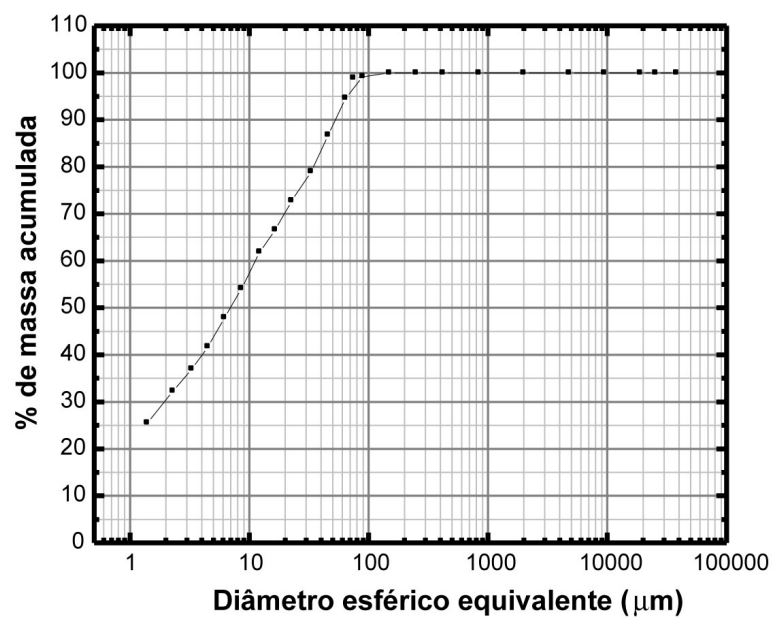

Figura 3: Curva de distribuição de tamanho de partículas primárias da massa cerâmica estudada.

[Figure 3: Primary particle size distribution curve of the studied ceramic paste.]

O processo de microgranulação de massas cerâmicas proporciona a obtenção de aglomerados de partículas. Estes aglomerados aumentam a compacidade, bem como a escoabilidade da massa cerâmica na etapa de compactação [15]. A Fig. 4 mostra a distribuição de tamanhos de grânulos da massa cerâmica. Verifica-se que a massa cerâmica apresentou a maior fração dos grânulos dentro do intervalo compreendido entre 150-250 $\mu \mathrm{m}$. Tem sido reportado que este intervalo de tamanho de grânulos é considerado adequado no processo via seca, resultando na obtenção de produtos de qualidade análogos aos obtidos pelo processo via úmida [16].

Para acompanhar o processo de densificação da massa cerâmica foi construído o diagrama de gresificação, conforme mostrado na Fig. 5. Este diagrama permite também avaliar a tolerância da massa a variações de temperatura e condições de processamento [17]. Além disso, serve como uma ferramenta de controle de qualidade de massas cerâmicas. Nota-se que, tanto a absorção de água, quanto a retração linear da massa cerâmica permanece praticamente inalterada dentro de um certo intervalo de temperatura $\left(1080-1100{ }^{\circ} \mathrm{C}\right)$. Este comportamento está relacionado à presença de carbonatos de cálcio e/ou magnésio na massa cerâmica alterando o curso das reações que ocorrem, sobretudo a altas temperaturas. São formadas fases cristalinas, que não são produzidas em sua ausência, que interferem nas reações de formação de 


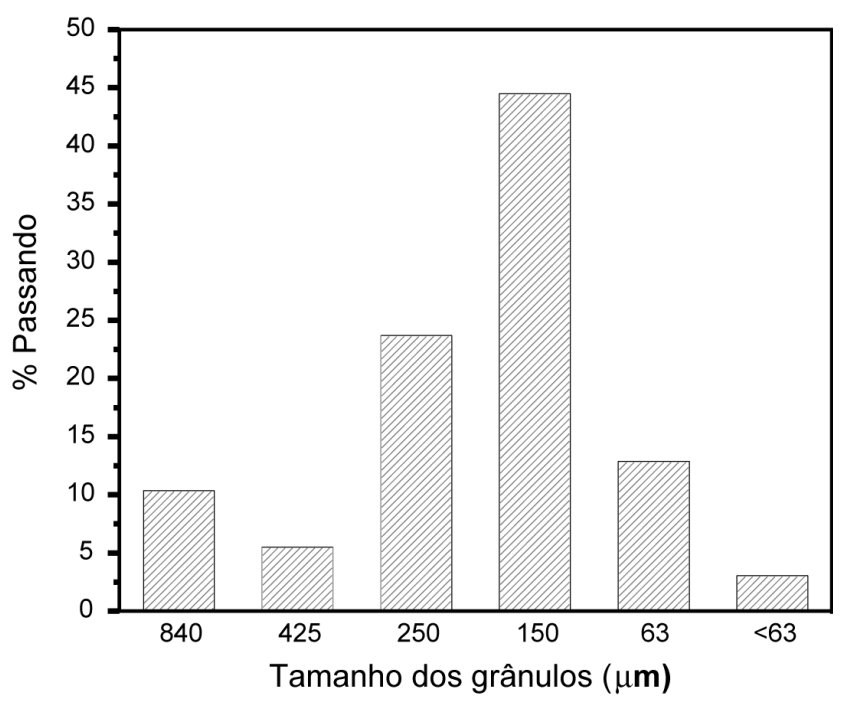

Figura 4: Distribuição de tamanho de partículas da massa cerâmica granulada.

[Figure 4: Particle size distribution of the granulated ceramic paste.]

fase líquida [18]. Primeiramente, ocorre decomposição dos carbonatos para formar $\mathrm{CaO}$ ou $\mathrm{MgO}$ com liberação de $\mathrm{CO}_{2}$. Estes óxidos reagem com sílica e alumina, procedentes da decomposição dos argilominerais, para formar fases cristalinas à base de cálcio e/ou magnésio (silicatos e aluminossilicatos). A partir de $1100{ }^{\circ} \mathrm{C}$ pode-se observar um aumento da retração linear com concomitante diminuição da absorção de água. Este comportamento está relacionado ao aumento de fase líquida que irá preencher progressivamente os poros abertos, e consequientemente provocar uma maior aproximação entre as partículas, resultando em retração dos corpos cerâmicos a medida que se aumenta a temperatura de sinterização.

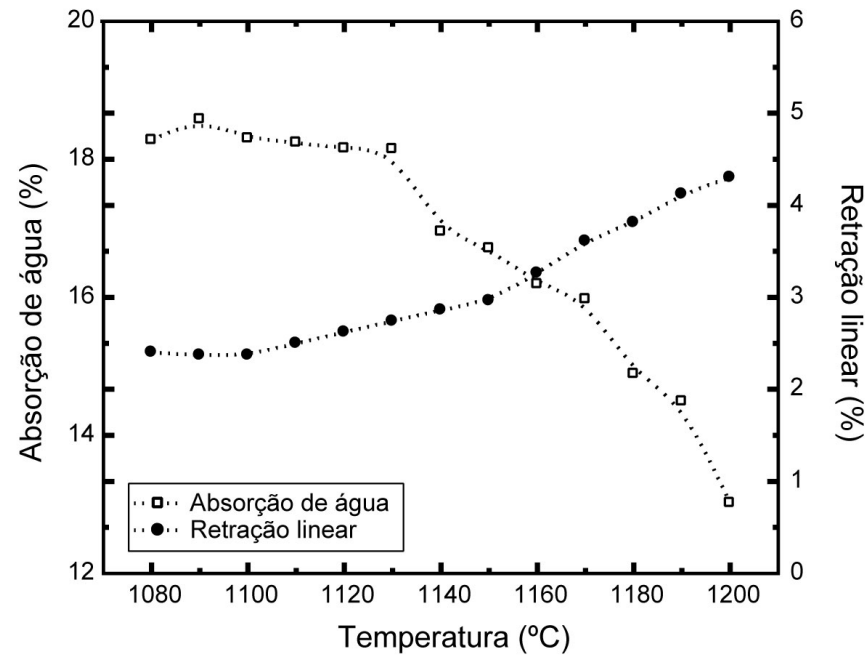

Figura 5: Diagrama de gresificação da massa cerâmica estudada. [Figure 5: Gresification diagram of the studied ceramic paste.]
A Fig. 6 mostra a influência da temperatura de sinterização sobre a massa específica aparente. Observa-se que de 1080 até $1110^{\circ} \mathrm{C}$ a massa específica é praticamente inalterada. A partir de $1110{ }^{\circ} \mathrm{C}$ começa a ocorrer um ligeiro aumento da massa específica aparente das peças cerâmicas. Esta influência da temperatura fica mais evidenciada a partir de $1120{ }^{\circ} \mathrm{C}$, onde os valores desta propriedade começam a aumentar de forma mais expressiva. Com base nestas observações, fica evidente o efeito dos óxidos de cálcio e de magnésio $(\mathrm{CaO}$ e $\mathrm{MgO})$, gerados na decomposição de carbonatos de cálcio e/ou magnésio, em retardar o processo de densificação da massa cerâmica até a temperatura de $1110^{\circ} \mathrm{C}$. A partir daí, o talco passa a auxiliar a densificação, promovendo um aumento da formação de fase líquida [19], aumentando assim a massa específica aparente das peças cerâmicas sinterizadas.

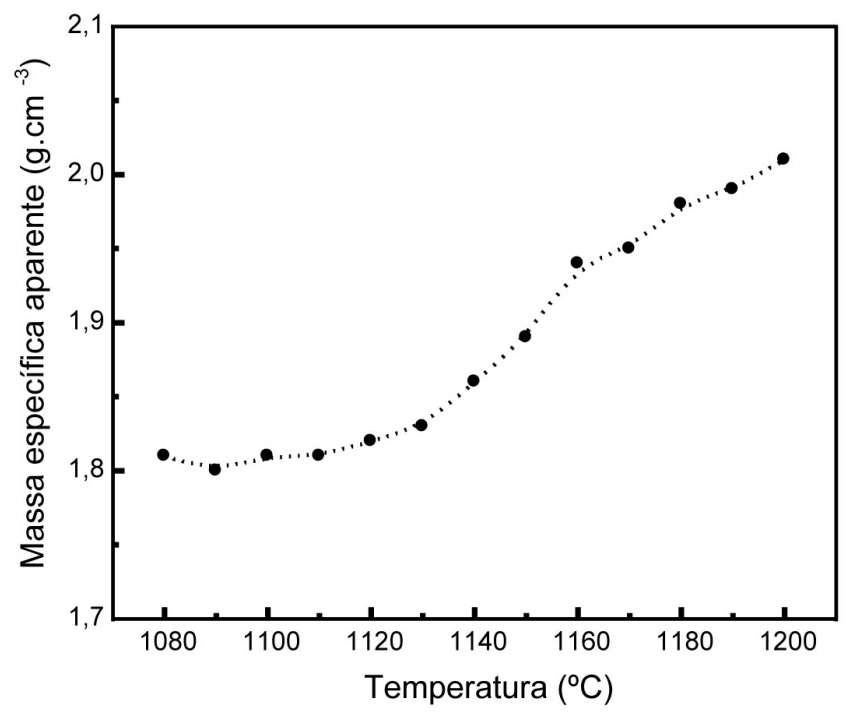

Figura 6: Massa específica aparente em função da temperatura de sinterização.

[Figure 6: Apparent specific mass as a function of sintering temperature.]

A influência da temperatura de sinterização sobre a tensão de ruptura à flexão dos corpos cerâmicos é mostrada na Fig. 7. Nota-se que, a medida que se aumenta a temperatura de sinterização ocorre um aumento na tensão de ruptura à flexão da massa cerâmica. Este comportamento está relacionado a dois fatores: o primeiro deles é a formação de fases cristalinas à base de cálcio e/ou magnésio (silicatos e aluminossilicatos). Estas fases possuem elevada resistência mecânica [20]. Um outro fator que contribui para o aumento da resistência mecânica das peças sinterizadas é a presença de talco na composição da massa cerâmica que assume o papel de fundente auxiliando a densificação e proporcionando fechamento da porosidade aberta.

A Fig. 8 mostra a microestrutura característica da superfície de fratura, após ensaio de flexão (carregamento em três pontos), dos corpos cerâmicos sinterizados em duas temperaturas distintas. Em $1140{ }^{\circ} \mathrm{C}$ (Fig. 8a), notase claramente uma estrutura altamente porosa típica de 


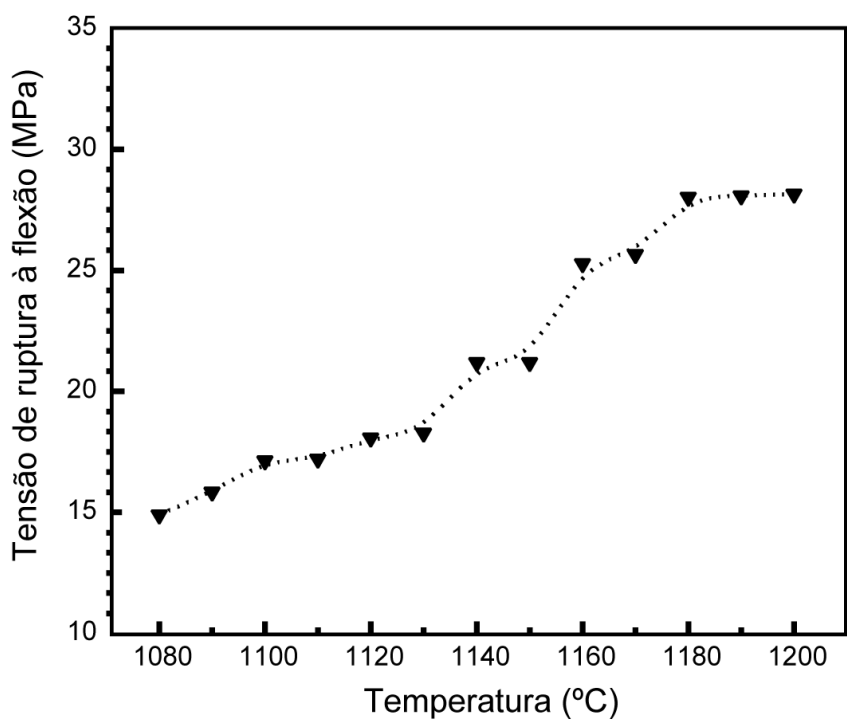

Figura 7: Tensão de ruptura à flexão em função da temperatura de sinterização.

[Figure 7: Flexural strength as a function of sintering temperature.]

revestimento cerâmico poroso (BIII). Enquanto que em $1200{ }^{\circ} \mathrm{C}$ (Fig. 8b), pode ser observado que ocorreu a eliminação de parte da porosidade aberta. Esta microestrutura porosa é importante para obtenção das propriedades físico-mecânicas de revestimento poroso, e reflete provavelmente a interação dos componentes das matériasprimas usadas em alta temperatura [21].

Com base nos resultados mostrados anteriormente e na norma NBR 13818, é possível avaliar o potencial de utilização da massa cerâmica estudada para fabricação de revestimento do tipo poroso. No presente trabalho, as peças sinterizadas apresentaram uma espessura média da ordem de $6,75 \mathrm{~mm}$. Assim, a massa cerâmica estudada atingiu as especificações de revestimento poroso (BIII) a partir da temperatura de $1090{ }^{\circ} \mathrm{C}$, em termos da absorção de água $(10-20 \%)$ e da tensão de ruptura à flexão (> $15 \mathrm{MPa})$. Além disso, os corpos cerâmicos apresentaram boa estabilidade dimensional durante a sinterização.

\section{CONCLUSÕES}

Os resultados experimentais deste trabalho demonstram claramente o potencial das matérias-primas cerâmicas do Norte Fluminense para fabricação de revestimento cerâmico poroso (BIII).

Amassa cerâmica preparada pelo processo via seca apresentou um bom nível de cominuição. Dessa forma, a reatividade entre os diversos constituintes da massa cerâmica foi favorecida. Além disso, o processo de microgranulação resultou numa distribuição de tamanho de grânulos adequada e boa escoabilidade da massa, facilitando a etapa de compactação.

Ficou evidente o efeito dos óxidos de cálcio e/ou magnésio, gerado na decomposição de carbonatos, em retardar o processo de densificação dos corpos cerâmicos
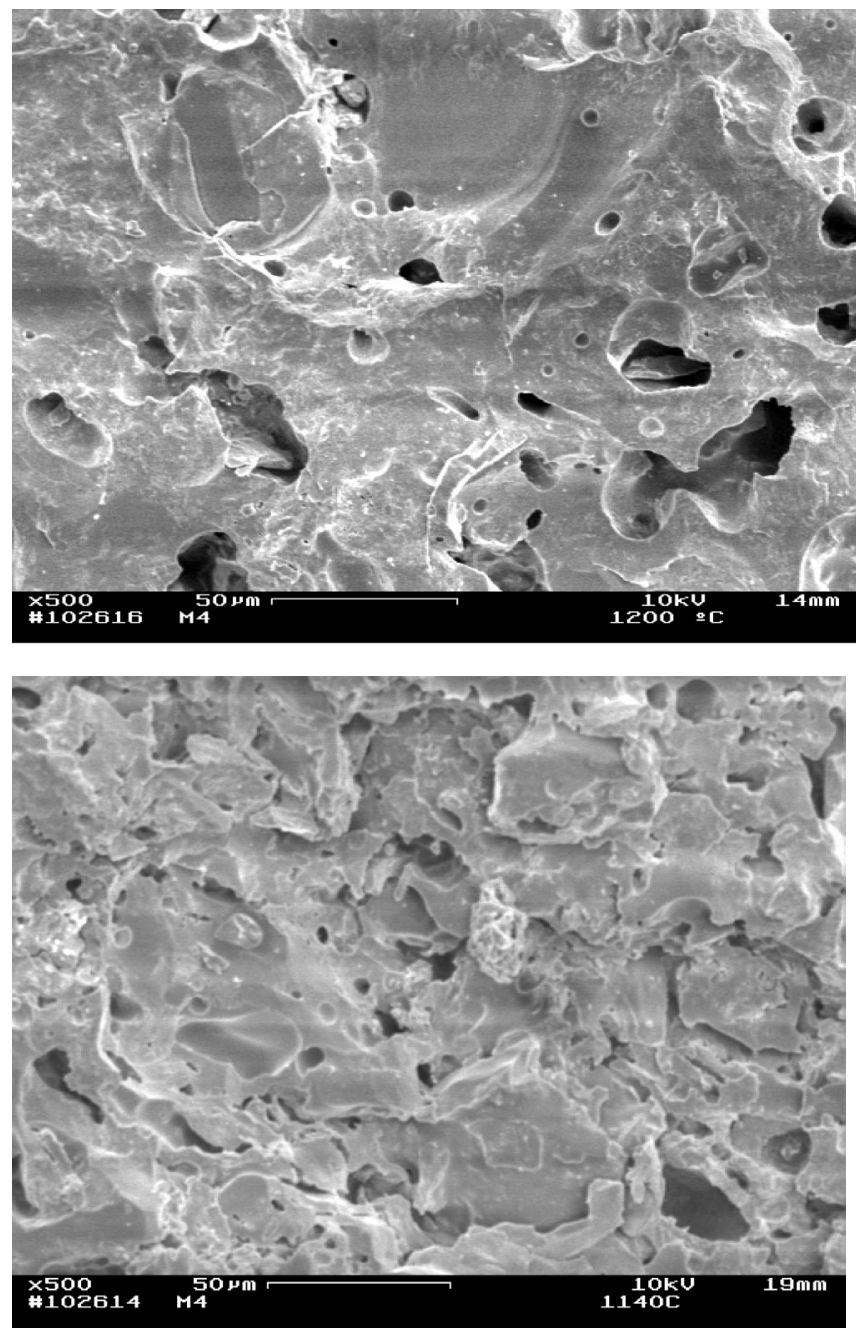

Figura 8: Micrografias MEV dos corpos cerâmicos sinterizados: a) $1140{ }^{\circ} \mathrm{Ce} \mathrm{b)} 1200{ }^{\circ} \mathrm{C}$.

[Figure 8: SEM micrographs of the sintered ceramic bodies: a) $1140^{\circ} \mathrm{C}$ and $\left.b\right) 1200{ }^{\circ} \mathrm{C}$.]

sinterizados entre $1080-1110{ }^{\circ} \mathrm{C}$. A partir desta temperatura, o talco adicionado na composição da massa cerâmica acelerou o processo de densificação. Isto influenciou significativamente as propriedades físico-mecânicas dos corpos sinterizados. Além do mais, os corpos cerâmicos apresentaram boa estabilidade dimensional neste intervalo de temperatura com valores de retração linear variando de 2,37 até $2,40 \%$ e absorção de água de 18,28 até $18,58 \%$. A microestrutura sinterizada evidenciou a alta porosidade típica de revestimento poroso. Além disso, de acordo com a NBR 13818, foram atingidas as especificações para revestimento poroso (BIII) em termos da absorção de água e da tensão de ruptura à flexão dos corpos cerâmicos sinterizados.

\section{AGRADECIMENTOS}

Os autores agradecem a CAPES e ao CNPq (Processo 551478/2002-0) pelo apoio a este trabalho. 


\section{REFERÊNCIAS}

[1] J. F. M. Motta, M. Cabral Júnior, L. C. Tanno, A. Zanardo, Ceram. Ind. 7, 1 (2002) 33-40.

[2] ABNT, NBR 13818, Placas Cerâmicas para Revestimento: Métodos de Ensaios e Especificações (1997).

[3] A. Escardino, Tile \& Brick Int. 9, 1 (1993) 14-19.

[4] A. P. N. Oliveira, Ceram. Ind. 5, 6 (2000) 37-47.

[5] S. Cava, C. A. Paskocimas, E. Longo, Anais do $45^{\circ}$ Congresso Brasileiro de Cerâmica, Florianópolis, SC (2001) cdrom, 265-278.

[6] J. N. F. Holanda, C. M. F. Vieira, Mundo Cerâmico 82 (2002) 29-31.

[7] S. J. G. Sousa, Dissertação de Mestrado, Universidade Estadual do Norte Fluminense, PPGECM-CCT, Campos dos Goytacazes, RJ (2003).

[8] ABNT, NBR 7181-84, Solo: Análise Granulométrica (1984).

[9] R. T. Zauberas, H. G. Riella, Ceram. Ind. 6, 2 (2001) 40-45.

[10] L. F. B. Marino, A. O. Boschi, Ceram. Ind. 3, 4-6 (1998) 18-23.
[11] R. S. T. Manhães, L. T. Auler, M. S. Sthel, J. Alexandre, M. S. O. Massunaga, J. G. Carrió, D. R. dos Santos, E. C. da Silva, A. Garcia-Quiróz, H. Vargas, App. Clay Sci. 21 (2002) 303-311.

[12] C. Y. Chen, G. S. Lan, W. H. Tuan, Ceram. Int. 26 (2000) 715-720.

[13] K. Traoré, T.S. Kabré, P. Blanchart, Ceram. Int. 29, 4 (2003) 377-383.

[14] M. M. Jordán, T. Sanfeliu, C. de la Fuente, Appl. Clay Sci. 20 (2001) 87-95.

[15] G. Nassetti, G. Brighenti, H. Sillem, Ceram. Acta 4, 5-6 (1992) 31-44.

[16] L. Lolli, G. Nassetti, L. F. B. Marino, Ceram. Ind. 5, 2 (2000) 23-27.

[17] G. Nassetti, Tile \& Brick Int. 3 (1990) 15-20.

[18] F. G. Melchiades, E. Quinteiro, A. O. Boschi, Ceram. Ind. 1, 4-5 (1996) 30-31.

[19] K. Traoré, T. S. Kabré, P. Blanchart, Appl. Clay Sci. 17 (2000) 279-292.

[20] P. Grosjean, Interceram 5 (1986) 23-26.

[21] T. K. Mukhopadhyay, M. Das, S. Ghosh, S. Chakrabarti, S. Ghatak, Ceram. Int. 29 (2003) 587-59

(Rec. 16/03/2004, Rev. 19/10/2004, Ac. 11/01/2005) 